\title{
Pink Orange Red: interpretação, sentido e presença nas canções da banda Cocteau Twins
}

\author{
Aline Gabrielle Renner \\ Mestranda; Universidade de São Paulo, São Paulo, SP, Brasil \\ agabrieller@usp.br
}

\section{Marcelo Bergamin Conter}

Doutor; Instituto Federal Do Rio Grande do Sul, Alvorada, RS, Brasil

marcelo.conter@alvorada.ifrs.edu.br

\begin{abstract}
Resumo
Este artigo tem por objetivo analisar alguns movimentos de busca por sentido nas letras da banda escocesa Cocteau Twins efetuados por fãs na internet. A pronúncia indecifrável da vocalista Elizabeth Fraser, assim como o fato de a banda ter raramente divulgado as letras oficiais de suas canções, gerou grande especulação em sites e fóruns acerca de seus "sentidos ocultos". Num primeiro momento, propomos uma análise das interpretações da canção Pink Orange Red a partir dos conceitos de interpretação e superinterpretação de Umberto Eco. Em seguida, propomos pensar o método de composição de Fraser à luz da noção de "produção de presença", de Hans Ulrich Gumbrecht. A reflexão sobre o tema permite o questionamento das experiências possíveis com o potencial esgotamento da fruição sensorial da música na busca de sentido em seu elemento textual.
\end{abstract}

Palavras-chave

Comunicação. Música. Interpretação. Teoria das Materialidades. Cocteau Twins.

\section{Introdução}

A banda Cocteau Twins foi criada em 1979 por Robin Guthrie, Elizabeth Fraser e Will Heggie (baixista substituído em 1983 por Simon Raymonde), então jovens moradores da pequena cidade industrial de Grangemouth, na costa leste da Escócia. 0 conjunto teve uma 
extensa e produtiva carreira ${ }^{1}$ e ao longo de quase vinte anos, lançou nove discos e dezenas de EPs e singles. Apesar de ter causado grande impressão na crítica de música e exercido influência sobre diversas outras formações de rock e do chamado dreampop, a banda nunca alcançou o grande público (MANUCEAU, 2013). Muitas das referências à banda aludem aos vocais de Elizabeth Fraser, caracterizando-os como "fora deste mundo", "inacessíveis" e "abstratos" (SIMPSON, 2009). Estes adjetivos referem-se tanto à qualidade vocal de Fraser enquanto soprano quanto às letras supostamente sem sentido ou aparentemente improvisadas das canções compostas pela vocalista.

A indecifrabilidade das palavras vocalizadas por Fraser e mesmo sua performance cambiante geraram, a partir da década de 1990, grandes discussões em fóruns virtuais acerca da existência de sentido das canções da banda e de suas possíveis interpretações. A questão logo se tornou um objeto de especulação para a mídia e uma das características mais marcantes da banda. Este artigo pretende tecer algumas considerações sobre as relações conflituosas entre texto e música, linguagem verbal e materialidade sonora ${ }^{2}$ que surgem com os movimentos de identificação e atribuição de sentido às canções da banda Cocteau Twins. Para isto, trabalharemos, inicialmente, com os conceitos de interpretação e superinterpretação de Umberto Eco, analisando os esforços interpretativos na canção Pink Orange Red à luz das premissas dos limites da interpretação desse autor. Num segundo momento, traremos a Teoria das Materialidades de Hans Ulrich Gumbrecht para analisar criticamente a abordagem puramente hermenêutica da música. Nesse sentido, procuramos compreender a voz de Fraser como um instrumento produtor de sons não necessariamente verbais e refutar a concepção da voz na música como apenas um veículo para mensagens literais.

\section{Os limites da interpretação}

Elizabeth Fraser é uma soprano. Ouvindo-se discos de períodos distintos, contudo, percebe-se que Fraser explora sua voz de maneiras diferentes, cantando de maneira mais livre nos primeiros discos (Garlands, de 1982, e Head over heels, de 1983, principalmente) e adotando, posteriormente, um tom mais suave e lírico. Assim como sua voz, suas letras também sofreram mudanças ao longo da trajetória da banda. Contrariada com a repercussão

\footnotetext{
1 A banda sempre esteve vinculada ao selo 4AD, também criado em 1979. A sonoridade da banda acabou por se tornar o centro de gravidade estético das demais bandas do selo ao longo dos anos 1980, posto que só foi tomado pelo Pixies a partir de 1987 ao antecipar a onda do grunge e do rock alternativo da década de 1990. Para mais informações sobre a relação entre a banda Cocteau Twins e o selo 4AD, sugerimos a leitura do texto Searching for heaven, de Martin Aston, publicado na página da banda no catálogo online do selo: https://4ad.com/forewords/searchingforheaven/. Acesso em 21 mai. 2019.

2 O termo "materialidade sonora", neste trabalho, compreende os sons que compõem as canções da banda Cocteau Twins em sua qualidade formal, antes de serem representacionais. O termo provém da Teoria das Materialidades de Hans Urlich Gumbrect (2010), que será apresentada em seguida no corpo do texto.
} 
negativa à sua performance no primeiro disco (caracterizado como "obscuro" pela crítica musical, pois era quase impossível distinguir palavras nos sons que Fraser produzia), Fraser adotou processos de composição propositalmente inacessíveis, ora utilizando palavras provenientes de outros idiomas e cujo sentido ignorava, ora criando neologismos baseados somente em sua materialidade sonora. Ainda, a cantora explorava seu sotaque escocês para distorcer a pronúncia das palavras, trocando a ênfase das sílabas tônicas e pronunciando-as como bem entendesse. Essa prática só foi abandonada, ainda que não completamente, nos últimos três discos da banda: Heaven or Las Vegas (de 1990), Four-calendar café (de 1993) e Milk and kisses (de 1996).

Em 1993, durante entrevista à rádio inglesa 1FM, Elizabeth Fraser afirmou, respondendo à onipresente questão sobre a origem de suas letras: “[...] as letras são palavras que encontrei folheando livros e dicionários escritos em línguas que não entendo [...] elas não têm sentido algum [...]" (FRASER, 1993b, tradução nossa ${ }^{3}$ ). Esta foi uma das diversas ocasiões em que a vocalista expôs seu desconforto com a constante busca por sentidos ocultos em suas canções, afirmando que era justamente esse esforço detetivesco um dos fatores que a estimulavam a compor letras que não possuíssem, de fato, sentido algum. Na mesma ocasião, ela admitiu que em sua escrita musical, a materialidade sonora das palavras predomina sobre seu significado. Em outra ocasião, entrevistada pela revista Mondo 2000, Fraser afirmou:

Combinando palavras de diferentes idiomas que eu não conseguia entender apenas significava que eu podia concentrar-me no som e não ficar presa no sentido [...] Mas isso era ainda mais divertido porque eu podia inventar muitos portmanteaus, literalmente centenas e centenas de palavras. Eu realmente gostava disso... E isso só foi ficando maior e maior. [...] Elas [as palavras] não significam nada, entretanto, essa é a questão. Você conhece todos os sons transcendentais. É só som, do início ao fim. (FRASER, 1993a, tradução nossa) ${ }^{4}$.

Mesmo quando os sons vocalizados por Fraser começam a ser inteligíveis nos últimos anos da banda, percebe-se o uso constante de metáforas e jogos de linguagem que mantêm, na opinião da crítica e dos fãs, obscuras e ambíguas as letras. Conforme Jean-Christophe Manuceau (2013), após o disco Blue bell knoll (de 1988), as músicas seguintes passaram a ser cada vez mais acessíveis, no sentido de que Fraser passou a articular as palavras de

\footnotetext{
3 No original: “[...] the lyrics are words I found by going through books and dictionaries written in langagues that I don't [...] the words don't have any meaning at all [...]". Transcrição do áudio entre os tempos [00:00:36] e [00:00:50] do vídeo disponível em: https://www.youtube.com/watch?v=z4arnK6ZFck\&list=RDz4arnK6ZFck\#t=8.

4 No original: "Combining words in different languages that I couldn't understand just meant I could concentrate on the sound and not get caught up in the meaning [...]. But I got to have more fun because I was able to make up lots of portmanteaus, literally hundreds and hundreds of words. I was really into it...And so it just kept on getting bigger. [...] They don't mean anything, though, that's the thing. You know all the transcendent sounds. It's all sound all the way through".
} 
modo compreensível. Ainda assim, durante a performance de Bluebeard no programa The Tonight Show with Jay Leno, em 19945 , Fraser frustrou o público, que esperava uma performance fiel à versão de estúdio, na qual as palavras são claras e compreensíveis, pelo modo como "distorceu a música". 0 que se ouve assemelha-se a uma nova música: a vocalista brinca com a voz, visivelmente envolvida pelo som que produz misturado ao dos outros instrumentos. 0 que foi um motivo de irritação para alguns espectadores do programa parece-nos ser apenas a consequência do modo como Fraser canta: as palavras podem existir, mas não necessitam absolutamente ser inteligíveis para produzirem qualquer efeito; o sentido está na própria expressão do som, e não nas palavras.

Na obra Os limites da interpretação (2015), Umberto Eco introduz uma reflexão sobre a mudança de paradigma na crítica literária ocorrida a partir dos anos 1960, quando a discussão sobre o critério de definição dos textos deixou a perspectiva estruturalista em direção a uma pragmática da leitura e da estética da recepção, momento em que o "fantasma do leitor" se inseriu no centro de diversos debates a respeito do campo da interpretação. Eco dá continuidade aos conceitos introduzidos em obras precedentes como Lector in fabula (1979) e explora a distinção entre dois modelos abstratos de leitura de um texto: o uso e a interpretação. A interpretação ocorre quando se respeita a coerência do texto, considerando, no exercício interpretativo, seu contexto cultural e linguístico; o uso, por outro lado, pressupõe uma leitura que amplia o universo discursivo-textual.

Segundo Eco (1995), o debate hermenêutico clássico tinha por objetivo descobrir em um texto tanto o que o autor queria dizer quanto o que o texto dizia independentemente das intenções de seu autor. Apenas após aceitar a segunda possibilidade caberia questionar se o que se descobre é o que o texto diz em virtude de sua coerência textual ou o que os destinatários encontram em razão de seus próprios sistemas de expectativas. A segunda perspectiva pressupõe que os textos são obras abertas que aceitam infinitas interpretações e tem por exemplo paradigmático aquilo que Eco (2015) denomina de "deriva hermética". Assim, o autor identifica três tipos de intenções operantes: a interpretação como pesquisa da intentio auctoris (a intenção do autor) ou da intentio operis (a intenção da obra) e a interpretação como imposição da intentio lectoris (realizada pelo destinatário do texto de acordo com seu próprio sistema de significação).

Eco identifica ainda a postura semiótica hermética no modelo abstrato do leitor que, segundo termo utilizado por Richard Rorty, "sova" o texto para fazer prevalecer a intentio lectoris. Nesse sentido, há diferença entre uma interpretação "sã" e uma interpretação

5 A performance está disponível no YouTube, publicada sem permissão oficial. Vale conferir as discussões entre fãs na lista de comentários: https://www.youtube.com/watch?v=z4arnK6ZFck\&list=RDz4arnK6ZFck\#t=8. Acesso em: mai. 2018. 
"paranoica": para Eco (ECO, 2015, p. 33), conquanto se possa dizer que haja uma relação entre as palavras "enquanto" e "crocodilo", pois ambas estão na mesma frase, o sujeito da interpretação paranoica deduzirá desta relação mínima o máximo possível, interrogando-se sobre as razões misteriosas que induziram o autor a colocar os dois termos lado a lado, fazendo inclusive inferências sobre seus aspectos biográficos.

O objetivo de Eco é afirmar a existência de alguns critérios limitadores que impedem que um texto seja "sovado" até a forma que sirva a um determinado intérprete, ou ainda a sua superinterpretação em uma espiral especulativa potencialmente infinita. Ainda que um texto possa ter múltiplos sentidos, disso não se infere que ele possa ter qualquer sentido, visto que "Os limites da interpretação coincidem com os direitos do texto (o que não quer dizer que coincidam com os direitos do autor)." (ECO, 2015, p. XXII).

\section{Interpretações das letras de Cocteau Twins}

As considerações de Umberto Eco aqui exploradas servem de substrato para uma análise comparativa de algumas das interpretações feitas das canções da banda Cocteau Twins por fãs em sites e fóruns virtuais, assim como pelo próprio selo da gravadora responsável pela distribuição dos discos da banda no Japão. Michael Borum é o responsável pelo site Cocteau Twins Lyrics Interpretations ${ }^{6}$, dedicado à interpretação das letras da banda. Diversos sites especializados em letras musicais apropriam-se dessas interpretações e divulgam-nas como versões oficiais, sendo comum encontrar mais de uma versão para a mesma letra.

Constata-se que a interpretação dessas canções ocorre de modo peculiar, pois trata-se, na maioria das vezes, de interpretar os próprios sons que Fraser emite e traduzi-los em um código comum. Em seu artigo Spooning good singing gum: meaning, association and interpretation in rock music, Travis Jackson (2000) refere-se aos processos interpretativos pelo público da banda como uma tentativa de interpretar as gravações "[...] baseada primeiramente nos sons, e secundariamente em informações sobre o grupo e seu processo criativo." (JACKSON, 2000, p. 28, tradução nossa ${ }^{7}$ ). Não raro as discussões sobre os possíveis sentidos das letras de Fraser envolvem especulações sobre dados biográficos dos membros da banda.

Um dos exemplos evidentes do esforço interpretativo ocorre na letra da música Pink Orange Red, do EP Tiny Dynamine (lançado como um duplo juntamente com o Echoes in a

\footnotetext{
Disponível em: https://cocteautwins.com/lyrics/. Acesso em: 11 nov. 2019.

No original: "[...] based primarily on the sounds and secondarily on information about the group and its creative process."
} 
Shallow Bay em 1985). Para a primeira estrofe desta música, o site de Michael Borum traz uma tradução dos vocais de Fraser (Tradução 1), enquanto nos sites SongMeanings ${ }^{8}$ e Metro Lyrics ${ }^{9}$, encontramos outra versão completamente diferente da mesma estrofe (Tradução 2), conforme comparação verso a verso no Quadro 1:

Quadro 1 - Comparação entre as traduções sonoras da música Pink Orange Red

\begin{tabular}{|c|c|}
\hline Tradução 1 (Cocteau Twins & Tradução 2 (SongMeanings e Metro \\
Interpretations) & Lyrics) \\
\hline Endrosis - osis & He draws his horses \\
Lotella - ella & Pretend that you're anger \\
Endrosis - osis & And draws his horses \\
Vivigeossa - ossa & Being chosen also \\
{$[\ldots]$} & {$[\ldots]$} \\
\hline
\end{tabular}

Fonte: Elaborado pelos autores.

Parece improvável tamanha discrepância na grafia de uma mesma música; todavia, escutando-se atentamente a faixa, é possível chegar à conclusão de que Fraser poderia estar cantando qualquer uma destas versões, ou nenhuma delas. A discrepância segue nos dois refrãos:

Quadro 2 - Comparativo das traduções sonoras da música Pink Orange Red

\begin{tabular}{|c|c|}
\hline Tradução 1 (Cocteau Twins & Tradução 2 (SongMeanings e Metro \\
Interpretations) & Lyrics) \\
\hline Meliteae & Please get up \\
phoebus hyala & Fall, please get up \\
cloeyessa & Don't ruin yourself \\
{$[\ldots .]$.} & {$[\ldots]$} \\
Hymeae & In my heart \\
saturnia & Set you right up \\
hymeae & In my heart \\
nossinussa & I sing this song \\
& \\
Vacua & Back you up \\
venessula & How messed I am \\
\hline
\end{tabular}

8 Disponível em: www.songmeanings.com. Acesso em: 11 mar. 2019.

9 Disponível em: www.metrolyrics.com. Acesso em: 11 mar. 2019. 


\begin{tabular}{|c|c|}
\hline vacua & Back you up \\
nekitella & I consider \\
Tuphia & So he got up \\
venessa & I must see him \\
enovalla & And all got up \\
& \\
Sacyare & Sore got he \\
oponalla & Apalled got up \\
hyniassa & I'm in this song \\
{$[. .]$.} & {$[. .]$.} \\
\hline
\end{tabular}

Fonte: elaborado pelos autores.

Em primeira análise, as palavras grafadas na Tradução 1 podem não fazer sentido algum; na realidade, como apontado no site Cocteau Twins Interpretations, elas correspondem a nomes científicos de espécies de borboletas, referências constantes em ambos os EPs Tiny Dynamine e Echoes in a Shallow Bay. A Tradução 2, por outro lado, reflete um esforço de adaptação do som a palavras pertencentes a um código comum - a língua inglesa. 0 resultado sugere que o ouvinte-interpretante da versão 2 tenha levado em consideração conhecimentos prévios sobre o contexto da banda e dos próprios músicos para entender os sons de maneira a construir um texto plausível para uma música de dreampop ${ }^{10}$ - a música trataria de uma decepção amorosa.

Podem-se compreender ambos os EPs Echoes in a Shallow Bay e Tiny Dynamine como textos em si, organismos que guardam mútuas relações de coerência. Retomando-se os critérios para a intentio operis de Eco, tem-se que a Tradução 1 leva em consideração as inúmeras referências a borboletas e mariposas evidentes em ambos os EPs, seja no título das canções (Great spangled fritillary, Pale clouded white, Melonella e Plain tiger são nomes de espécies dessa ordem de insetos), seja no próprio corpo textual (como ocorre nas músicas Sultitan itan e mesmo Pink Orange Red). Percebe-se que não apenas a versão 1 é coerente com o texto dos EPs, como também é apoiada nas declarações da própria Fraser, que admitia o hábito de compor utilizando termos encontrados em dicionários estrangeiros e enciclopédias visando à construção de textos em que prevalecia a materialidade sonora no lugar da semântica, como já vimos.

\footnotetext{
${ }^{10}$ Embora a questão do gênero musical ao qual pertenceria a Cocteau Twins não seja uma questão absolutamente clara, visto que a banda tem diversas influências e momentos, adotamos o entendimento de Daniela Fischer, que refere o gênero dreampop e caracteriza bem a sua paisagem sonora como etérea (FISCHER, 2013).
} 
Assim, remetendo-se novamente às noções de Eco, a versão 1 parece ter tanto a intentio auctoris quanto a intentio operis colaborando mutuamente, bem como está de acordo com o princípio de economia defendido pelo autor. Não se tratando de eleger a melhor interpretação, mas de descartar a menos plausível, temos, então, que a Tradução 1 guarda maior coerência com o texto sustentado pelos EPs, enquanto a versão 2 se aproxima do que Eco chama de uso do texto, pois parece-nos resultado de uma interpretação fundada fortemente na urgência do ouvinte (tradutor-interpretante) de encontrar um texto que produza sentido. Citamos novamente o autor:

Um texto "aberto" continua, ainda assim, sendo um texto, e um texto pode suscitar uma infinidade de leituras sem, contudo, permitir uma leitura qualquer [...] Depois que um texto foi produzido, é possível fazê-lo dizer muitas coisas - em certos casos, um número potencialmente infinito de coisas - mas é impossível - ou pelo menos criticamente ilegítimo - fazê-lo dizer o que não diz. Frequentemente os textos dizem mais do que o que seus autores pretendiam dizer, mas menos do que muitos leitores incontinentes gostariam que eles dissessem. (ECO, 2015, p. 81).

Discrepâncias como esta da faixa Pink Orange Red são muito comuns nas letras da banda. Em alguns casos os movimentos interpretativos parecem obter algum resultado excitante para quem busca sentidos ocultos. Esse é o caso da música Violaine, do álbum Milk and kisses (de 1996), na qual a possível tradução literal dos sons produz palavras inexistentes no vocabulário de qualquer língua, mas invertendo-se as letras de alguns termos, é possível identificar palavras da língua inglesa. Outro exemplo das discrepâncias na tradução e interpretação sonoras ocorre no primeiro verso da música In the gold dust rush, do disco Head over heels (1983). Aqui, encontramos duas versões, ambas tão possíveis quanto improváveis: para o primeiro verso da primeira estrofe, o site sugere o texto " $\mathrm{Her}$ honey mouth has got me awful bored", enquanto o site Metrolyrics sugere "Oh, honey my life it's got me old fool gold".

É importante considerar que não há uma interpretação definitiva e hermética que anule qualquer outra. Como Travis Jackson (2000) aponta, a própria banda parece distinguir interpretações que tentam definir, de modo rigoroso e definitivo, os significados do seu trabalho daquelas que provêm de um engajamento criativo com o som. Ela preferiria, segundo Jackson, que os ouvintes fizessem o que quisessem com as músicas, desde que não sobrecarregassem suas interpretações com respostas puramente associativas. Na realidade, nem Guthrie ou Raymonde (quando este não compunha as suas próprias letras) sabiam 
quais eram as palavras de Fraser. Sobre o assunto, Jackson cita um trecho da entrevista que Guthrie concedeu a Steve Sutherland, da revista Melody Maker, em 1990 ${ }^{11}$ :

As pessoas tendem a querer apenas que uma música seja uma mensagem. É só com o que elas podem lidar. Elas só querem tudo preto no branco. Por que elas não podem inventar as suas próprias ideias sobre o que algumas das músicas são - é isso o que eu faço. Eu tenho ideias sobre o que algumas músicas são. Elas provavelmente estão muito longe do que realmente são, mas pelo menos elas são minhas. (SUTHERLAND, 1990, p. 18 apud JACKSON, 2000, p. 27, tradução nossa) ${ }^{12}$

É possível verificar que até o guitarrista da banda tem suas próprias interpretações do que seriam os sons de Fraser. 0 problema ocorre quando há uma tentativa de definição forçosa das palavras e de seus significados, como ocorreu quando alguns discos da banda foram lançados no Japão. As políticas do selo subsidiário local exigiram que cada disco possuísse um encarte com as letras das músicas. Quando Fraser se recusou a cumprir a exigência, o selo contratou profissionais para transcreverem e traduzirem as letras, e o resultado causou enorme descontentamento para os músicos. Só o nome do disco já era indício da transfiguração empreendida: Treasure (1984) foi adaptado para The woman who the gods loved.

\section{Produção de presença}

A Teoria das Materialidades foi desenvolvida no final da década de 1980 por pesquisadores do Departamento de Literatura Comparada da Universidade de Stanford, e seu maior expoente é Hans Ulrich Gumbrecht. 0 autor defende uma relação com o mundo que possa fundar-se também na presença, uma relação que oscile entre efeitos de presença e efeitos de sentido, visto que tanto presença quanto sentido coexistem em constante tensão. Com os conceitos de "materialidade", "não hermenêutico" e "presença", Gumbrecht (2012, p. 62) questiona a "[...] via intelectual de mão única, fundamentada e sustentada por uma compreensão limitada, porém totalizante, da hermenêutica [...]" como epistemologia única nas Artes e Humanidades.

Esta oscilação entre efeitos de presença e efeitos de sentido é uma característica fundamental da experiência estética, e o peso relativo dos dois efeitos varia conforme a

\footnotetext{
${ }^{11}$ SUTHERLAND, Steve. Cocteau Twins: Bringing Up Baby. Melody Maker. August 25, 1990. P. 16-18.

${ }^{12}$ No original: "People tend to just want one song to be one message. It's all they can handle. They just want it all in black and white. Why can't they make up their own ideas about what some of the songs are about-that's what I do. I've got ideas about what some of the songs are about. They're probably a million miles from what they actually are about, but at least they're mine, y'know."
} 
materialidade midiática de cada objeto da experiência estética: para Gumbrecht (2010), ao lermos um texto, a dimensão do sentido será sempre dominante em relação à da presença, mesmo que haja tensões ou interferências que o texto pode suscitar - no caso da poesia, esta tensão se agrava. Por outro lado, o autor acredita que na música a dimensão da presença sempre será predominante, ainda que determinadas estruturas musicais sejam capazes de evocar conotações semânticas. Tal suposição nos parece ser de difícil comprovação se consideramos o quão ampla a definição de música pode ser, especialmente depois da contribuição de John Cage para expandir seus limites para além do dito "silêncio" em 4'33".

Ao criticar o entendimento de seus colegas críticos e teóricos literários quanto à concepção da linguagem como algo que exige interpretação, que convida a atribuir “significados bem circunscritos às palavras" (GUMBRECHT, 2012, p. 62), o autor alemão defende a concepção da linguagem falada como uma realidade física, que toca e afeta não apenas nosso sentido auditivo, mas o corpo como um todo. Assim, o som toca nossa pele, “[...] mesmo que não entendamos o suposto significado de suas palavras.” (GUMBRECHT, 2012, p. 66). É ao deixarmo-nos, enquanto corpos, sermos tocados e afetados por outros corpos da realidade da experiência estética como epifania que acessamos, ainda que transitoriamente, a sensação de estarmos-no-mundo.

Nesse ponto, percebe-se a influência que a obra do medievalista Paul Zumthor exerce no pensamento de Gumbrecht, principalmente no que se refere às suas reflexões sobre a voz, a performance e o espaço (ZUMTHOR, 2007). Zumthor inicia suas investigações sobre a oralidade a partir de estudos no campo da literatura e da poesia medieval, mas é na fase tardia de seu trabalho que o autor desenvolve uma fenomenologia da voz, interessando-se pela sua qualidade físico-sensual e reconhecendo-a como modo de comunicação centrado no corpo (cf. GUMBRECHT, 2010).

Os conceitos de Gumbrecht trazidos nos parágrafos anteriores servem de base para uma breve análise da postura por vezes eminentemente hermenêutica (por parte do público, da imprensa e da própria indústria musical) em relação às canções da banda Cocteau Twins. Cabe mencionar que a busca por um efeito de presença se dá não apenas por Fraser em suas letras "sem sentido", mas também na guitarra de Guthrie, submetida à distorção e a uma série de efeitos (flangers, phasers, chorus, harmonizadores e delays digitais), fazendo com que a guitarra soe como múltiplas e densas camadas sonoras.

Nessa perspectiva, convém conceber a voz de Fraser não como um mero veículo de mensagens codificadas que exigem uma interpretação literal, uma identificação e atribuição de sentido. Ao contrário, entendemos que a voz de Fraser pode ser pensada como uma materialidade, um instrumento em si capaz de tocar e afetar nossos corpos, 
independentemente da identificação desse som enquanto código capaz de produzir sentido. Lembramos o que Zumthor afirma sobre as relações entre corpo, voz e produção de sentido na performance: "A performance é uma realização poética plena: as palavras são tomadas num conjunto gestual, sonoro, circunstancial, tão coerente (em princípio) que, mesmo se distinguem mal palavras e frases, esse conjunto como tal faz sentido." (ZUMTHOR, 2005, p. 87). Assim, é feliz a definição da sonoridade da banda por Steve Sutherland (1985) em entrevista à revista Melody Maker: "instrumental com impressões vocais". A voz de Elizabeth Fraser funciona como um instrumento musical não verbal, tal como a guitarra, o baixo e a bateria $^{13}$. Ao invés de destacá-la diante dos instrumentos de corda e percussão, Fraser parece se esforçar em fazer com que sua voz se mescle com estes.

Há aí uma proposta de ruptura com o método tradicional de mixagem, que destaca a voz colocando-a à frente. Mas a banda Cocteau Twins enfrenta este método menos pelo equilíbrio de volume entre os elementos sonoros e mais pela ausência de sentido nos versos de Fraser. Mixar todos os elementos sonoros com o mesmo volume não é suficiente para efetuar uma "diluição" total entre voz e instrumentos, pois nossa mente e ouvidos estão aptos a analisar melhor as frequências sonoras médias, exatamente onde estão as vozes.

No mesmo sentido, no ensaio Language's duality and the rhetorical problem of music, Thomas Rickert (2005) analisa como a questão da dualidade da linguagem e sua relação com a música foi elaborada nas filosofias clássica e contemporânea, considerando como a relação entre música e retórica, apesar de sua existência conjunta, estabeleceu-se de modo desigual, com a preponderância da linguagem sobre o efeito da música. Para o autor, há “[...] uma tendência geral de supervalorização da razão sobre o sentimento, do sentido determinado sobre o efeito indeterminado, e de formas controladas de estética sobre as mais imprevisíveis." (RICKERT, 2005, p. 159, tradução nossa) ${ }^{14}$.

Rickert enfatiza que suas considerações sobre o tema são necessariamente abertas, pois música e efeito, enquanto experiências subjetivas, tendem a permanecer indeterminados e a questão se complexifica diante da postura epistemológica dominante, que supervaloriza a racionalidade da linguagem e do sentido na música (como em qualquer outro modo de fruição estética) em detrimento de seu efeito. Sob essa perspectiva, o autor defende que as letras do grupo musical somente podem ser consideradas sem sentido sob uma perspectiva linguística, pois, sob a perspectiva musical, elas oferecem, sim, um efeito de sentido, suscitando variadas imagens mentais em cada ouvinte. Elas exploram a potência semiótica do não sentido, as semioses latentes na articulação entre sílabas e fonemas pouco

\footnotetext{
13 Disponível em: http://www.cocteautwins.com/html/media/print/mm nov85.html. Acesso em: 11 mar. 2019.

${ }^{14}$ No original: "[...] a general trend toward the overvaluation of reason over feeling, of determinate sense over indeterminate affect, and of more controlled aesthetic forms over the more unpredictable."
} 
ou nunca antes exploradas pela língua inglesa, remetendo a passagens dos livros de Lewis Carroll. Como provocação, resgatamos a afirmação de Eco (2015, XXII): "Sejamos realistas: não há nada de mais significativo do que um texto que se declara divorciado de sentido."

\section{Considerações finais}

As ideias expostas neste artigo são breves considerações sobre a dialética relação entre linguagem sonora e materialidade sonora, sobre o uso e a interpretação das letras das canções e sobre os efeitos de sentido e presença na música da banda Cocteau Twins. A exigência da publicação das letras juntamente com o lançamento dos discos ou os esforços tradutórios e interpretativos para decifrar os sons e codificá-los em palavras inteligíveis indicam uma postura forçosamente hermenêutica mesmo para objetos que projetam mais ênfase na produção de presença, como é o caso da sonoridade da banda.

É possível que a necessidade de interpretar e compreender os sentidos, de descobrir alguma verdade oculta naquilo que se mostra imediatamente obscuro seja um efeito da "cultura de sentido" sugerida por Gumbrecht. Concordamos com este autor quando sugere a redenção da experiência estética dos efeitos de presença: escutar a voz de Elizabeth Fraser assim como escutamos as camadas de guitarra de Guthrie e o baixo de Raymonde, deixar que nossos corpos sejam tocados e afetados pela materialidade da voz de Fraser sem perdermo-nos na busca pelo sentido dos sons.

Por outro lado, tendo em vista que a postura hermenêutica é culturalmente consolidada e que os textos musicais são tão importantes ou quase tão importantes quanto a materialidade sonora na experiência musical, são relevantes as considerações de Umberto Eco sobre os limites da interpretação. Ao defender uma forma de interpretação textual que não se reduz a uma infinita espiral de variantes, mas que propõe critérios para distinguir interpretações mais e menos adequadas ou "justas", as ideias de Eco servem de subsídio para a análise das interpretações de alguns versos das letras compostas por Fraser.

De um mecanismo para lidar com a insegurança até uma provocação às críticas da imprensa sobre suas composições, as letras de Fraser deixavam abertas as canções para que fossem entendidas como o ouvinte quisesse, e o engajamento criativo pelo público era bem aceito pela banda. Contudo, a postura detetivesca e incansável para desvendar as supostas mensagens ocultas sob os sons vocalizados por Fraser, sugerindo resultados considerados absurdos e até ofensivos pelos músicos, quando não cômicos, beira a interpretação paranoica, nos termos de Eco. Nesse sentido, os exemplos trazidos neste artigo apenas 
ilustram as inúmeras ocasiões em que as vocalizações de Fraser foram usadas ou superinterpretadas.

Afinal, que tipo de escuta é essa que necessita esgotar os significados do que a toca? Aliás, questionamos se é possível qualquer tipo de experiência estética quando se reduz a recepção a um vagar infinito em busca "[...] de secretos jogos de palavras, etimologias desconhecidas, associações incônscias, imagens ambíguas [...]" (ECO, 2015, p. 280). Parecenos que o fim último desses usos não é outro senão o apaziguamento da incapacidade de aceitar o ininteligível, o incompreensível. Afinal, como defende Gumbrecht (2010, p. 117): "[...] não existe emergência de sentido que não alivie o peso da presença."

\section{Referências}

COCTEAU TWINS. Bluebeard (Live). The Tonight Show with Jay Leno (NBC), 8 de abril de 1994. Vídeo (4min). Disponível em: https://www.youtube.com/watch? v=z4arnK6ZFck\&list=RDz4arnK6ZFck\&index=1. Acesso em: 11 mar. 2019.

COCTEAU TWINS. In the gold dust rush. Head over heels. Intérprete: Elizabeth Fraser. Londres: 4AD, 1983.

COCTEAU TWINS. Pink orange red. Tiny Dynamine. Intérprete: Elizabeth Fraser. Londres: 4AD, 1985.

ECO, U. Lector in fabula: a cooperação interpretativa nos textos narrativos. São Paulo: Perspectiva, 1979.

ECO, U. Interpretación y sobreinterpretación. Cambridge: Cambridge University Press, 1995.

ECO, U. Os limites da interpretação. São Paulo: Perspectiva, 2015.

FISCHER, D. F. Paisagens sonoras etéreas: o dreampop sob a perspectiva das materialidades da comunicação. 2013. Trabalho de conclusão de curso (Graduação em Comunicação Social) - Faculdade de Biblioteconomia e Comunicação, Universidade Federal do Rio Grande do Sul, Porto Alegre, 2013.

FRASER, E. Elizabeth talks about her lyrics. 1FM Radio. Londres: 1993b. Disponível em: https://www.youtube.com/watch?v=XTx8VnZBvDc. Acesso em: 11 mar. 2019.

FRASER, E. Obscured by words. Mondo 2000, Califórnia, set/dez. 1993a. Disponível em: http://www.cocteautwins.com/html/media/print/mondo_fall93.html. Acesso em: 11 mar. 2019.

GUMBRECHT, H. U. Graciosidade e estagnação: ensaios escolhidos. Rio de Janeiro:

Contraponto, 2012. 
GUMBRECHT, H. U. Produção de presença: o que o sentido não consegue transmitir. Rio de Janeiro: Contraponto, 2010.

JACKSON, T. A. Spooning good singing gum: meaning, association, and interpretation in rock music. In: BURFORD, M. Current Musicology, New York, Columbia University, n. 69, mar/jun. 2000.

MANUCEAU, J. Des punks célestes. Rosiers-en-Haye: Camion Blanc, 2013. Livro eletrônico, não paginado.

RICKERT, T. Language's duality and the rhetorical problem of music. In: BIZZEL, P.

Rhetorical agendas: political, ethical, spiritual. New Jersey: Lawrence Erlbaum, 2005, p. 157-163.

SIMPSON, D. Elizabeth Fraser: the Cocteau Twins and me. The Guardian, Reino Unido, 26 nov. 2009. Disponível em: https://www.theguardian.com/music/2009/nov/26/cocteautwins-elizabeth-fraser-interview. Acesso em: 11 mar. 2019.

SUTHERLAND, S. Worlds Apart. Melody Maker, Nov. 1985. Disponível em: http://www.cocteautwins.com/html/media/print/mm_nov85.html. Acesso em: 11 mar. 2019.

ZUMTHOR, Paul. Performance, recepção, leitura. Tradução de Jerusa Pires Ferreira e Suely Fenerich. São Paulo: Cosac Naify, 2007.

ZUMTHOR, Paul. Escritura e nomadismo: entrevistas e ensaios. São Paulo: Ateliê Editorial, 2005.

\title{
Pink Orange Red: interpretation, meaning and presence in Cocteau Twins' songs
}

\begin{abstract}
This paper aims to analyze some movements of interpretation of the lyrics of the Scottish band Cocteau Twins by their fans on the internet. The indecipherable pronunciation of the singer Elizabeth Fraser, as well as the fact that the band has rarely published the official lyrics of their songs has generated great speculation across sites and forums about the song's "hidden meanings". At first, we propose an analysis of the interpretations of the song Pink Orange Red based on Umberto Eco's concepts of interpretation and overinterpretation. Then, we propose to think about Fraser's writing method in light of Hans Ulrich Gumbrecht's notion of "production of presence". Reflecting upon this theme allows us to question the experiences possible with the potential exhaustion of the sensuous enjoyment of music in the search for meaning in its textual element.
\end{abstract}




\section{Keywords}

Communication. Music. Interpretation. Materialities of Communication. Cocteau Twins.

Recebido em 21/03/2019

Aceito em 11/06/2019 